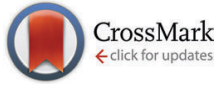

Cite this: Chem. Commun., 2015, 51, 1289

Received 7th November 2014, Accepted 26th November 2014

DOI: $10.1039 / \mathrm{c} 4 \mathrm{cc} 08808 \mathrm{e}$

www.rsc.org/chemcomm

\section{Designed supramolecular filamentous peptides: balance of nanostructure, cytotoxicity and antimicrobial activity $\dagger$}

\author{
Dawei $X u, \ddagger^{a}$ Linhai Jiang, $\ddagger^{a}$ Anju Singh, ${ }^{b}$ Derek Dustin, ${ }^{a}$ Miao Yang, ${ }^{a}$ Ling Liu, ${ }^{c}$ \\ Reidar Lund, ${ }^{d}$ Timothy J. Sellati ${ }^{b}$ and He Dong ${ }^{\star a}$
}

This work demonstrates a design strategy to optimize antimicrobial peptides with an ideal balance of minimal cytotoxicity, enhanced stability, potent cell penetration and effective antimicrobial activity, which hold great promise for the treatment of intracellular microbial infections and potentially systemic anti-infective therapy.

Naturally occurring antimicrobial peptides (AMPs) serve as the first line of host defense against a variety of microbial infections. ${ }^{1}$ A large number of AMPs consisting of both natural and non-natural amino acids have been de novo designed. ${ }^{2}$ In the past, the majority of work has focused on sequence variation and structural optimization of single peptide chains to achieve a balance between antimicrobial efficiency and selectivity. Successful design has and will continue to advance topical application of AMPs in clinically relevant settings. However, for systemic antimicrobial therapy using AMPs, particularly for the targeting of intracellular microbial pathogens, new strategies are highly desirable to overcome the intrinsic limitations associated with single peptide chains. Such limitations include cytotoxicity, protease susceptibility (for $\alpha$-peptides), poor cell penetration activity, and limited in vivo circulation half-life.

Peptide-based supramolecular assemblies represent an emerging and important class of biomaterials that have been extensively utilized in various biomedical fields, including drug delivery, ${ }^{3}$ vaccination, ${ }^{4} 3$-D cellular scaffolds, ${ }^{5}$ and antimicrobial hydrogels. ${ }^{6}$ Supramolecular peptides are assemblies of monomeric peptides held together by non-covalent interactions to form discrete nanostructures or nanostructured networks. Compared to single peptide chains, these large-scale assemblies have a distinctive mode of

\footnotetext{
${ }^{a}$ Department of Chemistry \& Biomolecular Science, Clarkson University, Potsdam, NY 13699, USA. E-mail: hdong@clarkson.edu

${ }^{b}$ Trudeau Institute, Saranac Lake, NY, 12983, USA

${ }^{c}$ Department of Mechanical and Aerospace Engineering, Utah State University, Logan, UT, 84322, USA

${ }^{d}$ Department of Chemistry, University of Oslo, 0315 Oslo, Norway

$\dagger$ Electronic supplementary information (ESI) available: Peptide synthesis, experimental procedures, CD, SEM, CMC fitting and cytotoxicity assay. See DOI: 10.1039/ c4cc08808e

\$ These authors contributed equally.
}

cellular interactions which can be tuned by adjusting peptide primary sequences and thus the intermolecular interactions between individual peptide chains. For example, the Stupp group has recently discovered that the supramolecular cohesion force in selected peptide amphiphiles has significant effects on cytotoxicity toward mammalian cell lines. ${ }^{7}$ Our group reported on the cell penetration activity of two cationic peptides which differ in their ability to self-assemble into supramolecular nanofibers. ${ }^{3 a}$ Nanofiber-forming peptides showed dramatically enhanced cell uptake compared to monomeric peptides. We have also observed dramatically different cytotoxicity profiles for fibrous peptides versus peptide monomers. Based on these preliminary results, we started to systematically evaluate the cytotoxicity, protease stability, and antimicrobial activity of these supramolecular peptides. The progress of this study may potentially lead to supramolecular AMPs with an ideal balance of minimal cytotoxicity, enhanced stability, potent cell penetration, and effective antimicrobial activity for the application of systemic anti-infective treatments.

The peptide sequences are based upon previously designed multidomain peptides (MDPs) with a general formula of $\mathrm{K}_{x}(\mathrm{QL})_{y} \mathrm{~K}_{z}$, which are cationic as well as amphiphilic. ${ }^{8}$ Unlike most AMPs that exist as a monomer prior to their binding with lipid membranes, MDPs can be formulated into soluble supramolecular nanofibers. The supramolecular nanostructure and stability can be tuned by adjusting the ratio between different blocks. The end products reflect an energetic balance between the intermolecular hydrogen bonding and hydrophobic interactions among the (QL) repeating units and electrostatic repulsion among the lysine residues. Scheme 1 shows a representative chemical structure of a MDP and its self-assembly into supramolecular nanofibers.

Three peptides were used in the current study, MDP-1 $\left(\mathrm{WK}_{2}(\mathrm{QL})_{6} \mathrm{~K}_{2}\right), 2\left(\mathrm{WK}_{3}(\mathrm{QL})_{6} \mathrm{~K}_{2}\right)$, and $3\left(\mathrm{~K}_{3} \mathrm{~W}(\mathrm{QL})_{6} \mathrm{~K}_{2}\right)$, which are designed to form supramolecular assemblies above a critical assembly concentration (CAC). For all the peptides, tryptophan (W) was incorporated for accurate concentration measurement. The position of $\mathrm{W}$ was also found to influence the molecular secondary structure, supramolecular nanostructure, stability, 


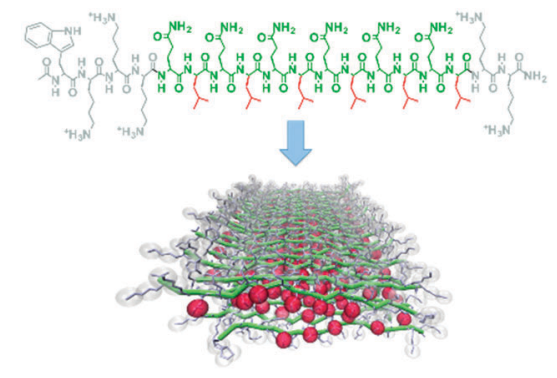

Scheme 1 Color-coded chemical structure of a MDP that can be designed to contain variable numbers of lysine residues and (QL) repeating units for the investigation of both molecular and supramolecular structure-dependent cytotoxicity and antimicrobial activity. Red: leucine; green: glutamine; grey: lysine.

and the antimicrobial activity of MDP-2 and MDP-3, which have identical amino acid compositions.

Fig. S1 (ESI $\dagger$ ) shows the circular dichroism (CD) spectra of all three peptides. The secondary structure of $\mathrm{WK}_{2}(\mathrm{QL})_{6} \mathrm{~K}_{2}$ (MDP-1) showed predominantly beta sheets as characterized by a single minimum peak at $216 \mathrm{~nm}$. Adding an additional lysine residue led to denaturation of ordered beta sheets into random coils more likely at both termini. For $\mathrm{WK}_{3}(\mathrm{QL})_{6} \mathrm{~K}_{2}$ (MDP-2), fitting of the CD spectrum gives rise to $41.4 \%$ beta sheets, $40 \%$ random coils and the rest being alpha helices. However, for $\mathrm{K}_{3} \mathrm{~W}(\mathrm{QL})_{6} \mathrm{~K}_{2}$ (MDP-3) with the same number of lysine residues as $\mathrm{WK}_{3}(\mathrm{QL})_{6} \mathrm{~K}_{2}$, switching the three $\mathrm{N}$-terminal lysine residues with $\mathrm{W}$ led to a restoration of beta sheet structure. This is largely due to the creation of the additional "KW" hydrophobic-hydrophilic repeating unit following the $(\mathrm{QL})_{6}$ domain at the $\mathrm{N}$ terminus so as to increase the driving force for beta sheet formation.

As shown in Fig. 1, all three peptides are capable of selfassembling into supramolecular nanofibers above their CACs. The CAC was determined by the previously established fluorescence self-quenching method where the fluorescence intensity of fluorescein labeled peptides was measured as a function of peptide concentration. ${ }^{9}$ Due to the formation of supramolecular assemblies, the fluorophores are in spatial proximity such that the change of the fluorescence intensity falls off the linear range and the cross point between the two regions is defined as the CAC. The CACs for MDP-1, 2, and 3 are $0.87 \mu \mathrm{M}, 1.24 \mu \mathrm{M}$ and $1.37 \mu \mathrm{M}$, respectively (Fig. S2, ESI $\dagger$ ).

The nanostructure formation is further confirmed and quantified in more detail using small-angle X-ray scattering (SAXS). The data were fitted on an absolute intensity scale using

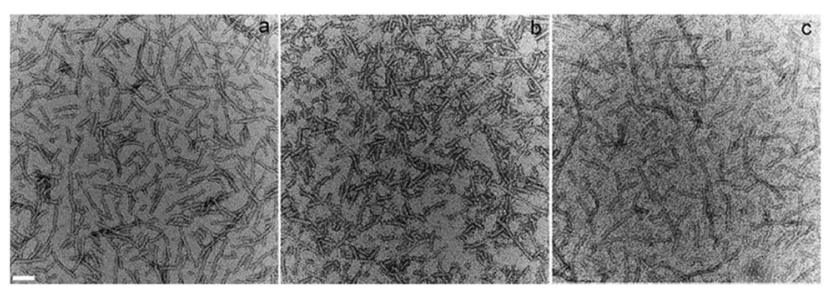

Fig. 1 TEM images of MDPs that self-assembled into supramolecular nanofibers. (a) $W K_{2}(Q L)_{6} K_{2}$ (b) $W K_{3}(Q L)_{6} K_{2}$ (c) $K_{3} W(Q L)_{6} K_{2}$. Peptide solution was prepared in Tris buffer $(\mathrm{pH}=7.4,20 \mathrm{mM})$ with a final peptide concentration at $100 \mu \mathrm{M}$. Scale bar: $50 \mathrm{~nm}$. a form factor of a regular platelet, i.e. long filaments, described by the three lengths, $a<b<c$. The SAXS data (Fig. S3, ESI $\dagger$ ) suggest rather well-defined fibers in solution with lengths $(c)$ of 40-50 nm, width $(b)$ of $5.8,6.7$, and $5.7 \mathrm{~nm}$, and height $(a)$ of 4.8, 4.7, and $2.7 \mathrm{~nm}$ for $\mathrm{WK}_{2}(\mathrm{QL})_{6} \mathrm{~K}_{2}, \mathrm{WK}_{3}(\mathrm{QL})_{6} \mathrm{~K}_{2}$ and $\mathrm{K}_{3} \mathrm{~W}(\mathrm{QL})_{6} \mathrm{~K}_{2}$, respectively. The fitting was greatly improved by incorporating a Gaussian distribution function describing a dispersion in $a$ of $\sim 28 \%, 35 \%$, and $20 \%$ respectively. The difference in the fiber dimensions was presumably due to the "edge" effect of the lysine residues adopting different molecular secondary structures. A non-canonical geometric model and fitting methods will be developed to elucidate the fine structure and packing of these nanofibers for future studies.

The cytotoxicity of the three MDPs and melittin, a naturally occurring AMP, was evaluated using primary mouse bone marrowderived monocytes (BMDMs). After $24 \mathrm{~h}$ of incubation with different peptides at concentrations of 1,5 , and $20 \mu \mathrm{M}$, released lactate dehydrogenase (LDH), an indicator of cell death, was quantified by ELISA (Fig. 2a and b). The percent cytotoxicity was calculated relative to the manufacturer-provided positive cell lysis control. Release of LDH from untreated BMDMs served as a negative control and this amount was subtracted from the positive control and peptidetreated groups. As shown in Fig. 2a, for all three MDP peptides, it was observed that an increase of peptide concentration above $1 \mu \mathrm{M}$ abolished the MDP's cytotoxicity. At first, this observation is quite surprising as it is contrary to dose-dependent relationships between concentration and cytotoxicity. Although the detailed molecular mechanism is unknown, we hypothesized that at low peptide concentrations, monomers/oligomers exist predominantly and they have the ability to insert into lipid membranes and cause membrane disruption and LDH leakage.

Such action is reminiscent of the working mechanism of most natural and synthetic single chained AMPs against both bacteria and mammalian cells. However, as peptide concentration increases, monomers/oligomers undergo self-assembly into supramolecular nanofibers. MDPs, having the characteristic of amyloid-like peptides, are more likely to follow the typical autocatalytic growth of nanofiber formation. ${ }^{8,10}$ Monomers/oligomers will be quickly consumed and organized into supramolecular nanofibers. MDP fibers are relatively short (below $100 \mathrm{~nm}$ ) due to the electrostatic repulsion so as to remain soluble in aqueous buffer, whereas typical amyloid-like peptides form elongated fibers on the order of at least micrometers in length and eventually precipitate out of the solution. Reduced cytotoxicity was mainly attributed to the formation of these supramolecular,

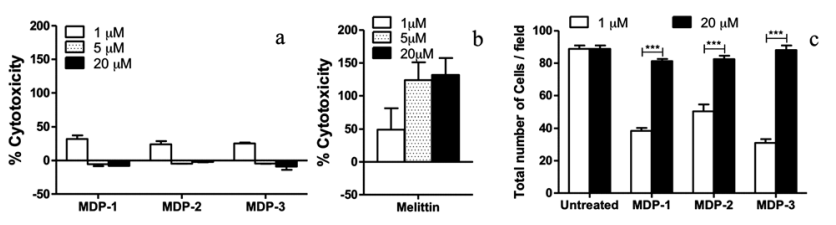

Fig. 2 (a) Effect of different MDPs on the viability of the BMDMs. (b) Effect of melittin on the viability of the BMDMs. (c) Quantitative analysis of the cytotoxic effect of MDPs on the BMDMs. Total number of cells observed after treatment of BMDMs with $1 \mu \mathrm{M}$ and $20 \mu \mathrm{M}$ of peptides were quantitated as compared to the uninfected control. Results are shown as the mean \pm SEM. ${ }^{* \star *} P<0.001$. 
short, soluble nanofibers which have been found to be more membrane permeable ${ }^{3 a}$ and therefore less cytotoxic. In contrast to the fiber-forming MDPs, as shown in Fig. 2b, melittin as a monomeric AMP, is highly cytotoxic and exhibits a dosedependent effect. In Fig. 2c the effect of exposure to 1 and $20 \mu \mathrm{M}$ MDP on the total number of cells per tissue culture well is presented. In accord with the $\mathrm{LDH}$ release results, exposure to $1 \mu \mathrm{M}$, but not $20 \mu \mathrm{M}$ MDP resulted in a significant decrease in cell numbers compared to untreated controls.

Recently, antimicrobial supramolecular assemblies have been designed based on the self-assembly of terephthalamide core bis-urea containing cationic polymers and small molecules. ${ }^{4 a, 11}$ Current work on the design of antimicrobial supramolecular peptides echoes these previous efforts for the construction of highly effective antimicrobial supramolecular biomaterials. Successful design of antimicrobial peptides beyond the molecular level will also complement conventional AMPs design and provide unique opportunities for treating intracellular bacterial infections, which is another topic being studied in our lab and will be reported separately.

The primary goal of this work is to demonstrate the antimicrobial effect of the designed supramolecular MDPs on bacterial viability and understand the influence of various physical and chemical parameters on antimicrobial efficiency. The antimicrobial activities of $\mathrm{WK}_{2}(\mathrm{QL})_{6} \mathrm{~K}_{2}, \mathrm{WK}_{3}(\mathrm{QL})_{6} \mathrm{~K}_{2}$, and $\mathrm{K}_{3} \mathrm{~W}(\mathrm{QL})_{6} \mathrm{~K}_{2}$ were tested against both gram negative bacteria, Escherichia coli and Pseudomonas aeruginosa and gram positive bacteria, Staphylococcus epidermidis and $S$. aureus. Peptides were co-incubated with each bacterial species for $18 \mathrm{~h}$ (for E. coli and P. aeruginosa) or $36 \mathrm{~h}$ (for $S$. aureus and $S$. epidermidis) and the UV absorbance at $600 \mathrm{~nm}$ was measured for the calculation of minimum inhibitory concentration (MIC) values. As shown in Table 1, based on the MIC results, $\mathrm{WK}_{3}(\mathrm{QL})_{6} \mathrm{~K}_{2}$ was found to have the most effective antimicrobial activity, followed by $\mathrm{K}_{3} \mathrm{~W}(\mathrm{QL})_{6} \mathrm{~K}_{2}$ and $\mathrm{WK}_{2}(\mathrm{QL})_{6} \mathrm{~K}_{2}$.

Different antimicrobial effects were also confirmed by a bacterial killing efficiency study where 99\% of gram negative bacteria were killed by $\mathrm{WK}_{3}(\mathrm{QL})_{6} \mathrm{~K}_{2}, 98 \%$ by $\mathrm{K}_{3} \mathrm{~W}(\mathrm{QL})_{6} \mathrm{~K}_{2}$, and less than $40 \%$ by $\mathrm{WK}_{2}(\mathrm{QL})_{6} \mathrm{~K}_{2}$ (Fig. S4, ESI $\dagger$ ). The same trend of killing activity was observed with gram-positive bacteria. Such order of activity inversely correlates with the peptides' tendency to form beta sheets and thus the stability of the supramolecular nanofibers. We believe that charge density plays a minimal role in the antimicrobial action of these supramolecular assemblies. MDP-2 and 3 have the exact same residue composition and charge density, yet they display dramatically different antimicrobial activities. A parallel study in our lab showed that

Table 1 MIC results of $\mathrm{WK}_{2}(\mathrm{QL})_{6} \mathrm{~K}_{2}, \mathrm{WK}_{3}(\mathrm{QL})_{6} \mathrm{~K}_{2}$, and $\mathrm{K}_{3} \mathrm{~W}(\mathrm{QL})_{6} \mathrm{~K}_{2}$ against E. coli, $P$. aeruginosa, $S$. aureus, and $S$. epidermidis showing sequence/ structure dependent antimicrobial activity

\begin{tabular}{|c|c|c|c|c|}
\hline \multirow[b]{2}{*}{ Peptide sequences } & \multicolumn{4}{|c|}{$\operatorname{MIC}(\mu \mathrm{M})$} \\
\hline & E. C. & P. A. & S. A. & S. E. \\
\hline $\mathrm{WK}_{2}(\mathrm{QL})_{6} \mathrm{~K}_{2}$ & $>80$ & $>80$ & $>80$ & 80 \\
\hline $\mathrm{WK}_{3}(\mathrm{QL})_{6} \mathrm{~K}_{2}$ & 20 & 20 & 10 & 5 \\
\hline $\mathrm{K}_{3} \mathrm{~W}(\mathrm{QL})_{6} \mathrm{~K}_{2}$ & 80 & 80 & 20 & 10 \\
\hline
\end{tabular}

D-amino acid substitution for the lysine residues on $\mathrm{WK}_{2}(\mathrm{QL})_{6} \mathrm{~K}_{2}$ slightly reduced beta sheet content and nanofiber integrity (data not shown). However, the antimicrobial efficiency was dramatically improved for the D-peptide although both $\mathrm{D}$ and $\mathrm{L}$ peptides contain the same number of charged residues. Additionally, the residual peptide monomer is not likely to contribute to the different antimicrobial activities observed since the CACs are quite low. More importantly, negligible amounts of monomers are expected in solution due to the consumption of monomers/oligomers in the process of autocatalytic growth of the nanofibers. Indeed, it is the intermolecular interactions between MDP building blocks that plays a key role in the membrane activity of these supramolecular assemblies and directly influences both primary cell viability and antimicrobial activity.

Scanning electron microscopy (SEM) was used to visualize the morphological change in bacteria with the addition of different MDPs. All three peptides were incubated with bacteria for $1 \mathrm{~h}$ before SEM imaging. Fig. S5 (ESI $\dagger$ ) shows the morphological changes in $E$. coli and $S$. aureus when exposed to peptides. Both $\mathrm{WK}_{3}(\mathrm{QL})_{6} \mathrm{~K}_{2}$ and $\mathrm{K}_{3} \mathrm{~W}(\mathrm{QL})_{6} \mathrm{~K}_{2}$ caused bacterial cell damage and confirmed the mode of antimicrobial activity through membrane disruption. $\mathrm{WK}_{2}(\mathrm{QL})_{6} \mathrm{~K}_{2}$, however, showed negligible membrane disruption as compared to control.

A significant concern of peptides composed of natural amino acids is their protease susceptibilities. Peptides consisting of nonnatural amino acids, such as D-amino acids, ${ }^{12} \beta$-amino acids, ${ }^{2 i, l} \alpha / \gamma$ AA amino acids, ${ }^{2 f, 13}$ and peptoids ${ }^{14}$ have been successfully designed and synthesized to solve the issue of protease stability, although the cost of their production may be prohibitive for general widespread use. More recently, peptide nanofilaments and nanobeacons were shown to have different enzymatic degradation rates. ${ }^{15}$ Consistent with this recent discovery, our results demonstrate that the supramolecular assembly can be used as another effective approach to improve the protease susceptibilities of antimicrobial peptides containing naturally occurring $\alpha$-amino acids. As shown in Fig. 3, peptides without enzymatic treatment were eluted as a major singlet at $\sim 17 \mathrm{~min}$. The three MDPs showed differing proteolytic stability upon incubation with two common enzymes, trypsin and chymotrypsin for $18 \mathrm{~h}$ and the degradation products of each peptide were monitored by HPLC.

For $\mathrm{WK}_{2}(\mathrm{QL})_{6} \mathrm{~K}_{2}$, a larger fraction of materials remained intact in the presence of these enzymes. With the addition of a single lysine residue, $\mathrm{WK}_{3}(\mathrm{QL})_{6} \mathrm{~K}_{2}$ exhibited dramatically

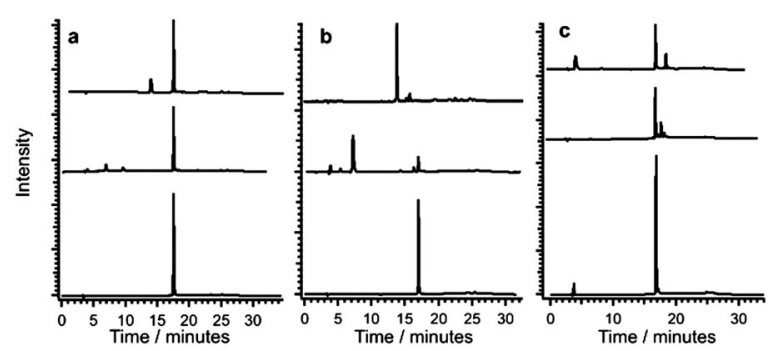

Fig. 3 Proteolytic stability of MDPs monitored by HPLC. (a) $W K_{2}(Q L)_{6} K_{2}$ (b) $\mathrm{WK}_{3}(\mathrm{QL})_{6} \mathrm{~K}_{2}$ (c) $\mathrm{K}_{3} \mathrm{~W}(\mathrm{QL})_{6} \mathrm{~K}_{2}$. Bottom trace: peptide without the addition of enzymes; middle: trypsin; top: chymotrypsin. 
diminished stability as demonstrated by a HPLC peak shift upon enzymatic treatment. However, the enzymatic stability was retrieved for $\mathrm{K}_{3} \mathrm{~W}(\mathrm{QL})_{6} \mathrm{~K}_{2}$, which has a larger fraction of beta sheets and therefore greater supramolecular stability. Quantitative results of the percentage of degradation are summarized in Table S1 (ESI $\dagger$ ). The resistance to proteolytic degradation observed here strongly correlates with the peptides' ability to self-assemble into supramolecular nanostructures. The refined nanostructures are likely to create steric hindrance for the proteases to access the active reaction sites thereby reducing degradation. Additionally, in the presence of serum, MDP-1 and MDP-2 with higher beta sheet contents are more stable than MDP-3 with reduced beta sheet character (Fig. S6, ESI $\dagger$ ). A summary of the molecular structures and biological activities of MDP nanofibers was shown in Fig. S7 (ESI $\dagger$ ). It can be envisioned that through co-assembly of different sequenced MDPs, an ideal balance between supramolecular nanostructure, protease stability, cytotoxicity, and antimicrobial activity could be achieved.

In conclusion, supramolecular peptide assemblies have been demonstrated to be a viable platform for the design and synthesis of AMPs that can strike a balance between structure, stability, cytotoxicity, and antimicrobial activity. Herein, we provided a new paradigm for functional AMP design to enhance the effectiveness of anti-infective treatments. Fundamental understanding of the structure-activity correlation beyond the molecular level will push forward the application of conventional AMPs in topical antiinfective therapy. It will also engender enormous opportunities for AMPs-based systemic antimicrobial treatments where both stability and cytotoxicity have been significant concerns to date. In addition, successful design of supramolecular AMPs will greatly advance the development of suitable strategies for combating intracellular microbial infection where the cell penetration activity of AMPs plays a key role for effective treatments. Future work should focus on models of intracellular bacterial infection using these supramolecular peptide assemblies and related work has been initiated in our lab.

Clarkson University is acknowledged for the support of this work. This work was supported by the Trudeau Institute, Inc. and NIH grant AI100138 to T.J.S. H.D. and T.J.S thank the CUTIP fund to support the project. We would like to thank Michael Tighe at the imaging core facility at Trudeau Institute for excellent technical support. The European Synchrotron Radiation Facility (ESRF) is acknowledged for allocation of beamtime at the BM29 beamline. We are grateful to Dr Martha Brennich for technical assistance at the instrument. R.L. greatly acknowledges grants from the Norwegian Research Council, under the SYNKNØYT program (218411 and 228573).

\section{Notes and references}

1 (a) Y. Shai, Biochim. Biophys. Acta, Biomembr., 1999, 1462, 55; (b) M. Zasloff, Nature, 2002, 415, 389; (c) R. E. W. Hancock and H.-G. Sahl, Nat. Biotechnol., 2006, 24, 1551.

2 (a) Z. Y. Ong, S. J. Gao and Y. Y. Yang, Adv. Funct. Mater., 2013, 23, 3682; (b) Y. Liu, Y. Yang, C. Wang and X. Zhao, Nanoscale, 2013, 5, 6413; (c) J. Kuriakose, V. Hernandez-Gordillo, M. Nepal, A. Brezden, V. Pozzi, M. N. Seleem and J. Chmielewski, Angew. Chem., Int. Ed., 2013, 52, 9664; (d) Z. Hayouka, S. Chakraborty, R. Liu, M. D. Boersma, B. Weisblum and S. H. Gellman, J. Am. Chem. Soc., 2013, 135, 11748; (e) N. Wiradharma, U. Khoe, C. A. E. Hauser, S. V. Seow, S. Zhang and Y.-Y. Yang, Biomaterials, 2011, 32, 2204; $(f)$ Y. Niu, S. Padhee, H. Wu, G. Bai, L. Harrington, W. N. Burda, L. N. Shaw, C. Cao and J. Cai, Chem. Commun., 2011, 47, 12197; $(g)$ R. Rathinakumar, W. F. Walkenhorst and W. C. Wimley, J. Am. Chem. Soc., 2009, 131, 7609; $(h)$ H. Meng and K. Kumar, J. Am. Chem. Soc., 2007, 129, 15615; (i) M. A. Schmitt, B. Weisblum and S. H. Gellman, J. Am. Chem. Soc., 2006, 129, 417; $(j)$ J. M. Rausch, J. R. Marks and W. C. Wimley, Proc. Natl. Acad. Sci. U. S. A., 2005, 102, 10511; (k) Y. Chen, C. T. Mant, S. W. Farmer, R. E. W. Hancock, M. L. Vasil and R. S. Hodges, J. Biol. Chem., 2005, 280, 12316; (l) E. A. Porter, B. Weisblum and S. H. Gellman, J. Am. Chem. Soc., 2002, 124, 7324.

3 (a) M. Yang, D. Xu, L. Jiang, L. Zhang, D. Dustin, R. Lund, L. Liu and H. Dong, Chem. Commun., 2014, 50, 4827; (b) R. H. Zha, S. Sur and S. I. Stupp, Adv. Healthcare Mater., 2013, 2, 126; (c) R. Lin, A. G. Cheetham, P. Zhang, Y.-a. Lin and H. Cui, Chem. Commun., 2013, 49, 4968; (d) A. G. Cheetham, P. Zhang, Y.-a. Lin, L. L. Lock and H. Cui, J. Am. Chem. Soc., 2013, 135, 2907; (e) H. Dong, N. Dube, J. Y. Shu, J. W. Seo, L. M. Mahakian, K. W. Ferrara and T. Xu, ACS Nano, 2012, 6, 5320; $(f)$ A. Trent, R. Marullo, B. Lin, M. Black and M. Tirrell, Soft Matter, 2011, 7, 9572; $(g)$ S. Soukasene, D. J. Toft, T. J. Moyer, H. Lu, H.-K. Lee, S. M. Standley, V. L. Cryns and S. I. Stupp, ACS Nano, 2011, 5, 9113.

4 (a) K. Fukushima, S. Liu, H. Wu, A. C. Engler, D. J. Coady, H. Maune, J. Pitera, A. Nelson, N. Wiradharma, S. Venkataraman, Y. Huang, W. Fan, J. Y. Ying, Y. Y. Yang and J. L. Hedrick, Nat. Commun., 2013, 4, 2861; (b) J. S. Rudra, S. Mishra, A. S. Chong, R. A. Mitchell, E. H. Nardin, V. Nussenzweig and J. H. Collier, Biomaterials, 2012, 33, 6476; (c) J. S. Rudra, Y. F. Tian, J. P. Jung and J. H. Collier, Proc. Natl. Acad. Sci. U. S. A., 2010, 107, 622.

5 (a) D. M. Ryan, T. M. Doran, S. B. Anderson and B. L. Nilsson, Langmuir, 2011, 27, 4029; (b) R. N. Shah, N. A. Shah, M. M. Del Rosario Lim, C. Hsieh, G. Nuber and S. I. Stupp, Proc. Natl. Acad. Sci. U. S. A., 2010, 107, 3293; (c) J. Liu, H. Song, L. Zhang, H. Xu and X. Zhao, Macromol. Biosci., 2010, 10, 1164; (d) K. M. Galler, L. Aulisa, K. R. Regan, R. N. D'Souza and J. D. Hartgerink, J. Am. Chem. Soc., 2010, 132, 3217; (e) H. Cui, M. J. Webber and S. I. Stupp, Pept. Sci., 2010, 94, 1; $(f)$ Z. Yang and B. Xu, Adv. Mater., 2006, 18, 3043; $(g)$ J. P. Schneider, D. J. Pochan, B. Ozbas, K. Rajagopal, L. Pakstis and J. Kretsinger, J. Am. Chem. Soc., 2002, 124, 15030.

6 (a) D. A. Salick, D. J. Pochan and J. P. Schneider, Adv. Mater., 2009, 21, 4120; (b) D. A. Salick, J. K. Kretsinger, D. J. Pochan and J. P. Schneider, J. Am. Chem. Soc., 2007, 129, 14793.

7 C. J. Newcomb, S. Sur, J. H. Ortony, O.-S. Lee, J. B. Matson, J. Boekhoven, J. M. Yu, G. C. Schatz and S. I. Stupp, Nat. Commun., 2014, 5, 3321.

8 H. Dong, S. E. Paramonov, L. Aulisa, E. L. Bakota and J. D. Hartgerink, J. Am. Chem. Soc., 2007, 129, 12468.

9 (a) H. Dong, J. Y. Shu, N. Dube, Y. Ma, M. V. Tirrell, K. H. Downing and T. Xu, J. Am. Chem. Soc., 2012, 134, 11807; (b) M. Kastantin, B. Ananthanarayanan, P. Karmali, E. Ruoslahti and M. Tirrell, Langmuir, 2009, 25, 7279.

10 H. Dong and J. D. Hartgerink, Biomacromolecules, 2007, 8, 617.

11 K. Fukushima, J. P. K. Tan, P. A. Korevaar, Y. Y. Yang, J. Pitera, A. Nelson, H. Maune, D. J. Coady, J. E. Frommer, A. C. Engler, Y. Huang, K. Xu, Z. Ji, Y. Qiao, W. Fan, L. Li, N. Wiradharma, E. W. Meijer and J. L. Hedrick, ACS Nano, 2012, 6, 9191.

12 (a) G. Carmona, A. Rodriguez, D. Juarez, G. Corzo and E. Villegas, Protein J., 2013, 32, 456; (b) D. Wade, A. Boman, B. Wåhlin, C. M. Drain, D. Andreu, H. G. Boman and R. B. Merrifield, Proc. Natl. Acad. Sci. U. S. A., 1990, 87, 4761.

13 (a) Y. Niu, H. Wu, Y. Li, Y. Hu, S. Padhee, Q. Li, C. Cao and J. Cai, Org. Biomol. Chem., 2013, 11, 4283; (b) Y. Niu, S. Padhee, H. Wu, G. Bai, Q. Qiao, Y. Hu, L. Harrington, W. N. Burda, L. N. Shaw, C. Cao and J. Cai, J. Med. Chem., 2012, 55, 4003.

14 (a) R. Kapoor, M. W. Wadman, M. T. Dohm, A. M. Czyzewski, A. M. Spormann and A. E. Barron, Antimicrob. Agents Chemother., 2011, 55, 3054; (b) R. Kapoor, P. R. Eimerman, J. W. Hardy, J. D. Cirillo, C. H. Contag and A. E. Barron, Antimicrob. Agents Chemother., 2011, 55, 3058.

15 (a) L. L. Lock, A. G. Cheetham, P. Zhang and H. Cui, ACS Nano, 2013, 7, 4924; (b) Y.-A. Lin, Y.-C. Ou, A. G. Cheetham and H. Cui, Biomacromolecules, 2014, 15, 1419. 